than to the rise in saturation after bronchodilator treatment.

Oximetry seems to provide a rapid and accurate assessment of acute childhood asthma in the emergency department.

This study was supported by the Asthma Foundation of Western Australia and the TVW Telethon Foundation.
1 Lee DA, W'inslow NR, Speight ANP, Hey EN. Prevalence and spectrum of asthma in childhoed. Br. Hed F 1983;286:1258-60.

2 McFadden LR, Lyons HA. Arterial-blood gas tension in asthma. $N$ Engl.7 Med $1968 ; 278: 1027-32$

3 Burki NK, Albert RK. Noninvasive monitoring of arterial blend gases: a repor of the ACCP section on respiratory pathophysiology. Chest 1983;83:666-70. 4 Rebuck AS, Chapman KR, D'Urzo A. The accuracy and response characteristics of a simplified ear oximeter. Chest 1983:83:860-4.

Accepted 12 April 1988
Gastroenterology Unit, Department of Medicine, Westmead Hospital, Westmead, NSW 2145, Australia P I Craig, FRACP, research fellow

PE Gillespie, FRACP, consultant gastroenterologist

Correspondence and reprint requests to: Dr Craig.

\section{Through the endoscope balloon dilatation of benign gastric outlet obstruction}

\section{P I Craig, P E Gillespie}

Traditionally benign gastric outlet obstruction that has failed to settle with medical treatment has been corrected surgically.' The recent development of wire guided hydrostatic balloon dilators has offered an alternative to surgery, particularly in high risk patients. ${ }^{2}$ This technique, however, requires radiological control and fails in $26 \%$ of patients because of difficulties in positioning both the guidewire and subsequently the dilator through the stricture.' We report a recently developed endoscopic technique for managing this problem which does not require guidewire placement.

\section{Methods and results}

The procedure is usually performed during outpatient endoscopy. The system is composed of a $180 \mathrm{~cm}$ polyethylene catheter with a built in guidewire (Microvasive, Mass, USA). Near the tip is a low compliance balloon $2 \mathrm{~cm}$ long. A $10 \mathrm{ml}$ syringe is used to inflate the balloon with water; the inflation pressure is monitored by a gauge connected to the catheter. Balloon catheters of increasing diameter $(8-15 \mathrm{~mm})$ are introduced through a $2.8 \mathrm{~mm}$ or larger endoscope biopsy channel. They are positioned to lie across the stricture. The balloon is then inflated, held for 60 seconds, pulled back into the stomach, and then deflated. The procedure is repeated until the stricture is dilated to $15 \mathrm{~mm}$.

From June 1986 to October 198714 patients with benign gastric outlet obstruction were studied prospectively. Their mean age was 68 , and seven were either aged over 75 or had an associated serious illness which would have made an operation hazardous. Thirteen patients had symptoms, while one asymptomatic patient was found to have a pyloric stenosis during a procedure indicated for endoscopic sphincterotomy. Ten patients underwent a barium meal examination before dilatation. All had evidence of gastric outlet narrowing, and eight had gastric dilatation and barium retention. The diagnosis was confirmed in all patients by the failure to pass an $11 \mathrm{~mm}$ diameter endoscope through the stricture. Eleven patients had pyloric stenosis, two postbulbar duodenal obstruction, and one stenosis of both outlets of a Billroth 2 gastroenterostomy.

Dilatation was eventually successful in 13 of the 14 patients, as assessed by the passage of a therapeutic endoscope (outer diameter 11.5 or $12.8 \mathrm{~mm}$ ) through the stricture and improvement in symptoms. There were no complications. Patients required a mean of 1.9 (range 1-5) dilatation sessions, at six week intervals, to achieve a successful result. In the one failure the catheter could not be positioned through an eccentric stenosed pylorus. In seven patients a repeat barium meal three-12 weeks after successful dilatation showed

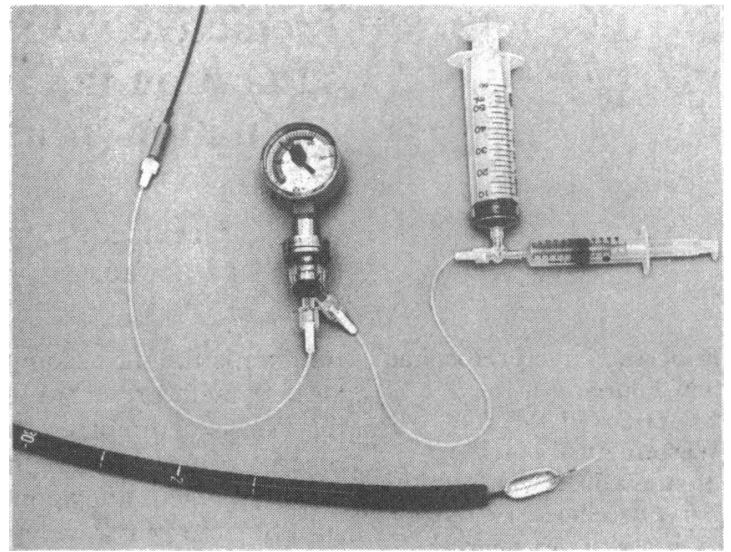

Inflated balloon catheter with pressure gauge and syringe assembly

improvement. Eleven of the successfully treated patients have continued long term treatment with ranitidine and the two others have remained well after only eight weeks' treatment. Despite symptomatic improvement further dilatations (mean 1.4) were performed in five patients because of endoscopic evidence of restenosis. The mean time of follow up was 10 (range 1-16) months. Four of the six patients followed up for over a year after successful dilatation remained well without recurrence, while two others required periodic dilatations to maintain endoscopic patency.

\section{Comment}

Earlier studies using wire guided hydrostatic balloon catheters resulted in symptomatic improvement in $67-83 \%$ of patients in whom stenoses were dilated. ${ }^{2.5}$ In contrast, $93 \%$ of all patients ( $100 \%$ of dilated patients) in this study achieved both symptomatic and objective evidence of improvement. The procedure was well tolerated and is technically easier to perform than wire guided dilatation. The correct timing for follow up dilatations is uncertain. Periodic procedures may be unnecessary for asymptomatic patients with endoscopic evidence of restenosis whereas symptomatic patients requiring repeated dilatations may eventually need surgery. The short term results support the use of this technique in high risk patients, but longer follow up is needed to assess its place in the definitive management of gastric outlet obstruction.

We thank Dr P N Francis for allowing us to include his patient.

1 Jaffin BW, Kaye MD. The prognosis of gastric outlet obstruction. Ann Surg 1985;201:176-9.

2 Benjamin SB, Glass RL, Cattau EL, Miller WB. Preliminary experience with balloon dilation of the pylorus. (jastromest Endosc 1984;30:93-5.

3 Lindor $\mathrm{KD}$, Ott BJ, Hughes RW. Balloon dilatation of upper digestive tract strictures. (Gastroenterolog' 1985;89:545-8.

+ Hogan RB, Hamilton JK. Polter DE. Preliminary experience with hydrostatic balloon dilation of gastric outlet obstruction. Gastrointest Endosc 1986;32: $71-4$

5 Kozarek RA. Hvdrostatic balleon dilation of gastrointestinal stenoses: a national survey. (jastrointest Endosc 1986;32:15-9.

Accepted 5 Mav 1988 